\title{
A MODIFIED SHRINKING PROJECTION METHODS FOR NUMERICAL RECKONING FIXED POINTS OF $G$-NONEXPANSIVE MAPPINGS IN HILBERT SPACES WITH GRAPHS
}

\author{
H.A. HAMMAD, W. CHOLAMJIAK, D. YAMBANGWAI, AND H. DUTTA \\ Received 30 April, 2019
}

\begin{abstract}
In this paper, we introduce four new iterative schemes by modifying the shrinking projection method with Ishikawa iteration and $S$-iteration. The strong convergence theorems are given for obtaining a common fixed point of two $G$-nonexpansive mappings in a Hilbert space with a directed graph. We also give some numerical experiments for supporting our main theorems and compare convergence rate between them.
\end{abstract}

2010 Mathematics Subject Classification: 47H10; 47H04

Keywords: strong convergence, shrinking projection, $G$-nonexpansive mappings, modified iterations, numerical discussion

\section{INTRODUCTION}

Let $C$ be a nonempty, closed and convex subset of a normed space $X$. A mapping $T: C \rightarrow C$ is said to be

1. contraction if there exists $\alpha \in(0,1)$ such that $\|T x-T y\| \leq \alpha\|x-y\|$ for all $x, y \in C$;

2. nonexpansive if $\|T x-T y\| \leq\|x-y\|$ for all $x, y \in C$.

The fixed point set of $T$ is denoted by $F(T)$, that is, $F(T)=\{x \in C: x=T x\}$.

The first important result on fixed points for contractive-type mapping was the well known Banach's contraction principle appeared in explicit form in Banach's thesis in 1922, where it was used to establish the existence of a solution for an integral equation [4]. Since this date, many articles studied and considered fixed point theorems and the existence of fixed points of a single-valued nonlinear mapping (see, for examples [2, 6, 22]).

In 1953, Mann [11] introduced the famous iteration procedure as follows:

$$
\begin{aligned}
x_{1} & \in C \\
x_{n+1} & =\delta_{n} x_{n}+\left(1-\delta_{n}\right) T x_{n},
\end{aligned}
$$


for all $n \in \mathbb{N}$ where $\left\{\delta_{n}\right\} \subset[0,1]$ and $\mathbb{N}$ the set of all positive integers. This iteration is used to obtain weak convergence theorem (see for example [16,18]).

In 1974, Ishikawa [8] generalized the Mann's iterative algorithm by introduce the following iteration:

$$
\begin{aligned}
x_{0} & \in C \\
x_{n+1} & =\delta_{n} x_{n}+\left(1-\delta_{n}\right) T y_{n}, \\
y_{n} & =\alpha_{n} x_{n}+\left(1-\alpha_{n}\right) T x_{n},
\end{aligned}
$$

for all $n \in \mathbb{N}$ where $\left\{\alpha_{n}\right\}$ and $\left\{\delta_{n}\right\}$ are sequences in $[0,1]$.

In 2007, Agarwal et al. [1] introduced and studied the $S$-iteration process for a class of nearly asymptotically nonexpansive mappings in Banach spaces and this scheme has a better convergence rate than Ishikawa iteration for a class of contractions in metric spaces.

In 2008, Takahashi et al. [23] just involved one closed convex set for a family of nonexpansive mappings $\left\{T_{n}\right\}$ and obtaining another modification of the Mann's iteration method:

$$
\begin{aligned}
u_{0} & \in H, u_{1}=P_{C_{1}} x_{0} \text { with } C_{1}=C, \\
y_{n} & =\alpha_{n} u_{n}+\left(1-\alpha_{n}\right) T_{n} u_{n}, \\
C_{n+1} & =\left\{z \in C_{n}:\left\|y_{n}-z\right\| \leq\left\|u_{n}-z\right\|\right\}, \\
u_{n+1} & =P_{C_{n+1}} x_{0} .
\end{aligned}
$$

They proved that if $\alpha_{n} \leq a$ for all $n \geq 1$ and for some $0<a<1$, then the sequence $\left\{u_{n}\right\}$ converges strongly to $P_{F i x(T)} x_{0}$.

In 2008, by combination of the concepts in fixed point and graph theory, Jachymski [9] generalized the Banach's contraction principle in a complete metric space endowed with a directed graph. Many papers dealt with this point for existence of fixed points of monotone nonexpansive, $G$-nonexpansive and $G$-contraction mappings on a hyperbolic metric, Banach and Hilbert spaces endowed with graph and directed graph. Also these articles discussed Browders convergence theorem for $G$ -nonexpansive mapping in a Hilbert space with a directed graph, weak and strong convergence of the Ishikawa iteration for $G$-nonexpansive mappings (see for example [3, 13, 24, 25]).

Motivated by the work of [1,25], Suparatulatorn et al. [20] studied the following modified $S$-iteration process:

$$
\begin{aligned}
x_{0} & \in C, \\
y_{n} & =\left(1-\sigma_{n}\right) x_{n}+\sigma_{n} S_{1} x_{n}, \\
x_{n+1} & =\left(1-\delta_{n}\right) S_{1} x_{n}+\left(1-\delta_{n}\right) S_{2} y_{n}, n \geq 0,
\end{aligned}
$$


where $\left\{\delta_{n}\right\}$ and $\left\{\sigma_{n}\right\}$ are sequences in $(0,1)$ and $S_{1}, S_{2}: C \rightarrow C$ are G-nonexpansive mappings. Also they proved weak and strong convergence for approximating common fixed points of two $G$-nonexpansive mappings in a uniformly convex Banach space $X$ endowed with a graph under this iteration.

Motivated and inspired by the above works, we introduce the four different iterative schemes by using the shrinking projection method for approximating a common fixed point of two $G$-nonexpansive mappings in Hilbert spaces. We then obtain strong convergence theorems. Finally, we discuss some important numerical results to illustrate the rate convergence of the four iterations.

\section{PRELIMINARiES AND LEMMAS}

In this section, we give some known definitions and lemmas which will be used in the later sections.

Let $C$ be a nonempty subset of a real Banach space $X$. Let $\triangle$ denote the diagonal of the cartesian product $C \times C$, i.e., $\triangle=\{(x, x): x \in \triangle\}$. Consider a directed graph $G$ such that the set $V(G)$ of its vertices coincides with $C$, and the set $E(G)$ of its edges contains all loops, i.e., $E(G) \supseteq \triangle$. We assume $G$ has no parallel edge. So we can identify the graph $G$ with the pair $(V(G), E(G))$. A mapping $S: G \rightarrow G$ is said to be

- $G$-contraction if $S$ satisfies the conditions:

(i) $S$ is edge-preserving, i.e.,

$$
(x, y) \in E(G) \Rightarrow(S x, S y) \in E(G),
$$

(ii) $S$ decreases weights of edges of $G$, i.e., there exists $\delta \in(0,1)$ such that

$$
(x, y) \in E(G) \Rightarrow\|S x-S y\| \leq \delta\|x-y\| .
$$

- $G$-nonexpansive if $S$ satisfies the condition (i) and

(iii) $S$ non-increases weights of edges of $G$, i.e.,

$$
(x, y) \in E(G) \Rightarrow\|S x-S y\| \leq\|x-y\| .
$$

Definition 1. The symbol $G^{-1}$ is called the conversion of a graph $G$ and it is a graph obtained from $G$ by reversing the direction of edges as:

$$
E\left(G^{-1}\right)=\{(x, y) \in X \times X:(y, x) \in E(G)\} .
$$

Definition 2. The sequence $\left\{x_{j}\right\}_{j=0}^{N}$ of $N+1$ vertices is called a path in $G$ from $x$ to $y$ of length $N(N \in \mathbb{N} \cup\{0\})$, where $x_{0}=x, x_{N}=y$ and $\left(x_{j}, x_{j+1}\right) \in E(G)$ for $j=0,1, \ldots, N-1$.

Definition 3. If there is a path between any two vertices of the graph $G$, then a graph $G$ is said to be connected.

Definition 4. If $(x, y)$ and $(y, z) \in V(G)$, then $(x, z) \in V(G)$. This property is called the transitivity of a directed graph $G=(V(G), E(G))$ for all $x, y, z \in V(G)$. 
Definition 5. Let $G=(V(G), E(G))$ be a directed graph. The set of edges $E(G)$ is said to be convex if for any $(x, y),(z, w) \in E(G)$ and for each $t \in(0,1)$, then $(t x+(1-t) z, t y+(1-t) w) \in E(G)$.

Definition 6. Let $x_{0} \in V(G)$ and $A$ subset of $V(G)$. We say that

(i) $A$ is dominated by $x_{0}$ if $\left(x_{0}, x\right) \in E(G)$ for all $x \in A$.

(ii) $A$ dominates $x_{0}$ if for each $x \in A,\left(x, x_{0}\right) \in E(G)$.

Lemma 1 ([19]). Let $C$ be a nonempty, closed and convex subset of a Hilbert space $H$ and $G=(V(G), E(G))$ a directed graph such that $V(G)=C$. Let $T: C \rightarrow$ $C$ be a G-nonexpansive mapping and $\left\{x_{n}\right\}$ be a sequence in $C$ such that $x_{n} \rightarrow x$ for some $x \in C$. If, there exists a subsequence $\left\{x_{n_{k}}\right\}$ of $\left\{x_{n}\right\}$ such that $\left(x_{n_{k}}, x\right) \in E(G)$ for all $k \in \mathbb{N}$ and $\left\{x_{n}-T x_{n}\right\} \rightarrow y$ for some $y \in H$. Then $(I-T) x=y$.

Let $C$ be a nonempty, closed and convex subset of a Hilbert space $H$. The nearest point projection of $H$ onto $C$ is denoted by $P_{C}$, that is, $\left\|x-P_{C} x\right\| \leq\|x-y\|$ for all $x \in H$ and $y \in C$. Such $P_{C}$ is called the metric projection of $H$ onto $C$. We know that the metric projection $P_{C}$ is firmly nonexpansive, i.e.,

$$
\left\|P_{C} x-P_{C} y\right\|^{2} \leq\left\langle P_{C} x-P_{C} y, x-y\right\rangle
$$

for all $x, y \in H$. Furthermore, $\left\langle x-P_{C} x, y-P_{C} x\right\rangle \leq 0$ holds for all $x \in H$ and $y \in C$; see [21].

We know that the following result.

Lemma 2. Let $H$ be a real Hilbert space. Then

$$
\|t x+(1-t) y\|^{2}=t\|x\|^{2}+(1-t)\|y\|^{2}-t(1-t)\|x-y\|^{2},
$$

for all $t \in[0,1]$ and $x, y \in H$.

Lemma 3 ([10]). Let $C$ be a nonempty, closed and convex subset of a real Hilbert space $H$. Given $x, y, z \in H$ and also given $a \in \mathbb{R}$, the set

$$
\left\{v \in C:\|y-v\|^{2} \leq\|x-v\|^{2}+\langle z, v\rangle+a\right\}
$$

is convex and closed.

Lemma 4 ([12]). Let $C$ be a nonempty, closed and convex subset of a real Hilbert space $H$ and $P_{C}: H \rightarrow C$ be the metric projection from $H$ onto $C$. Then the following inequality holds:

$$
\left\|y-P_{C} x\right\|^{2}+\left\|x-P_{C} x\right\|^{2} \leq\|x-y\|^{2}, \quad \forall x \in H, \forall y \in C .
$$

\section{MAIN RESULTS}

In this section, by using the shrinking projection method, we obtain four different strong convergence theorems for finding the same common fixed point of two $G$ nonexpasive mappings in real Hilbert spaces. 
Theorem 1. Let $C$ be a nonempty closed and convex subset of a real Hilbert space $H$ and let $G=(V(G), E(G))$ be a directed graph such that $V(G)=C$ and $E(G)$ is convex. Let $S_{1}, S_{2}: C \rightarrow C$ be $G$-nonexpansive mappings such that $F:=$ $F\left(S_{1}\right) \cap F\left(S_{2}\right) \neq \varnothing, F$ is closed and $F\left(S_{i}\right) \times F\left(S_{i}\right) \subseteq E(G)$ for all $i=1,2$. Let $\left\{s_{n}\right\}$ be a sequence generated by

$$
\begin{aligned}
s_{1} & \in C, \text { with } C_{1}=C, \\
y_{n} & =\left(1-\beta_{n}\right) s_{n}+\beta_{n} S_{1} s_{n}, \\
z_{n} & =\left(1-\alpha_{n}\right) s_{n}+\alpha_{n} S_{2} y_{n}, \\
C_{n+1} & =\left\{z \in C_{n}:\left\|z_{n}-z\right\| \leq\left\|s_{n}-z\right\|\right\}, \\
s_{n+1} & =P_{C_{n+1}} s_{1}, n \geq 1,
\end{aligned}
$$

where $\left\{\alpha_{n}\right\},\left\{\beta_{n}\right\} \subset[0,1]$. Assume that the following conditions hold:

(i) $\left\{s_{n}\right\}$ dominates $p$ for all $p \in F$ and if there exists a subsequence $\left\{s_{n_{k}}\right\}$ of $\left\{s_{n}\right\}$ such that $s_{n_{k}} \rightarrow w \in C$, then $\left(s_{n_{k}}, w\right) \in E(G)$;

(ii) $\liminf _{n \rightarrow \infty} \alpha_{n}>0$; (iii) $0<\liminf _{n \rightarrow \infty} \beta_{n} \leq \limsup _{n \rightarrow \infty} \beta_{n}<1$.

Then the sequence $\left\{s_{n}\right\}$ converges strongly to $P_{F} s_{1}$.

Proof. We split the proof into five steps.

Step 1. Show that $P_{C_{n+1}} s_{1}$ is well-defined for each $s_{1} \in C$. As shown in Theorem 3.2 of Tiammee et al. [24], $F\left(S_{i}\right)$ is convex for all $i=1,2$. It follows from the assumption that $F$ is closed and convex. Hence, $P_{F} s_{1}$ is well-defined. We see that $C_{1}=C$ is closed and convex. Assume that $C_{n}$ is closed and convex. From the definition of $C_{n+1}$ and Lemma 3, we get $C_{n+1}$ is closed and convex. Let $p \in F$. Since $\left\{s_{n}\right\}$ dominates $p$ and $S_{1}$ is edge-preserving, we have $\left(S_{1} s_{n}, p\right) \in E(G)$. This implies that $\left(y_{n}, p\right)=\left(\left(1-\beta_{n}\right) s_{n}+\beta_{n} S_{1} s_{n}, p\right) \in E(G)$ by $E(G)$ is convex. Since $S_{2}$ is edge-preserving, we have

$$
\begin{aligned}
\left\|z_{n}-p\right\| & \leq\left(1-\alpha_{n}\right)\left\|s_{n}-p\right\|+\alpha_{n}\left\|S_{2} y_{n}-p\right\| \\
& \leq\left(1-\alpha_{n}\right)\left\|s_{n}-p\right\|+\alpha_{n}\left(\left(1-\beta_{n}\right)\left\|s_{n}-p\right\|+\beta_{n}\left\|S_{1} s_{n}-p\right\|\right) \\
& \leq\left\|s_{n}-p\right\| .
\end{aligned}
$$

We can conclude that $p \in C_{n+1}$. Thus $F \subset C_{n+1}$. This implies that $P_{C_{n+1}} s_{1}$ is welldefined.

Step 2. Show that $\lim _{n \rightarrow \infty}\left\|s_{n}-s_{1}\right\|$ exists. Since $F$ is a nonempty, closed and convex subset of $H$, there exists a unique $v \in F$ such that $v=P_{F} s_{1}$. From $s_{n}=$ $P_{C_{n}} s_{1}$ and $s_{n+1} \in C_{n}, \forall n \in \mathbb{N}$, we get

$$
\left\|s_{n}-s_{1}\right\| \leq\left\|s_{n+1}-s_{1}\right\|, \quad \forall n \in \mathbb{N} .
$$

On the other hand, as $F \subset C_{n}$, we obtain

$$
\left\|s_{n}-s_{1}\right\| \leq\left\|v-s_{1}\right\|, \quad \forall n \in \mathbb{N} .
$$

It follows from (3.3) and (3.4) that the sequence $\left\{s_{n}\right\}$ is bounded and nondecreasing. Therefore $\lim _{n \rightarrow \infty}\left\|s_{n}-s_{1}\right\|$ exists. 
Step 3. Show that $s_{n} \rightarrow w \in C$ as $n \rightarrow \infty$. For $m>n$, by the definition of $C_{n}$, we see that $s_{m}=P_{C_{m}} s_{1} \in C_{m} \subset C_{n}$. From Lemma 4, we have

$$
\left\|s_{m}-s_{n}\right\|^{2} \leq\left\|s_{m}-s_{1}\right\|^{2}-\left\|s_{n}-s_{1}\right\|^{2} .
$$

From Step 3, we obtain that $\left\{s_{n}\right\}$ is a Cauchy sequence. Hence, there exists $w \in C$ such that $s_{n} \rightarrow w$ as $n \rightarrow \infty$. In particular, we have

$$
\lim _{n \rightarrow \infty}\left\|s_{n+1}-s_{n}\right\|=0 .
$$

Step 4. Show that $w \in F$. Since $s_{n+1} \in C_{n}$, it follows from (3.5) that

$$
\left\|z_{n}-s_{n}\right\| \leq\left\|z_{n}-s_{n+1}\right\|+\left\|s_{n+1}-s_{n}\right\| \leq 2\left\|s_{n+1}-s_{n}\right\| \rightarrow 0
$$

as $n \rightarrow \infty$. Since $\liminf _{n \rightarrow \infty} \alpha_{n}>0$ and (3.6), we have

$$
\left\|S_{2} y_{n}-s_{n}\right\|=\frac{1}{\alpha_{n}}\left\|z_{n}-s_{n}\right\| \rightarrow 0,
$$

as $n \rightarrow \infty$. From $\left\{s_{n}\right\}$ dominates $p$ for all $p \in F$ and Lemma 2, we get

$$
\begin{aligned}
\left\|z_{n}-p\right\|^{2} \leq & \left(1-\alpha_{n}\right)\left\|s_{n}-p\right\|^{2}+\alpha_{n}\left\|S_{2} y_{n}-p\right\|^{2} \\
\leq & \left(1-\alpha_{n}\right)\left\|s_{n}-p\right\|^{2}+\alpha_{n}\left(\left(1-\beta_{n}\right)\left\|s_{n}-p\right\|^{2}\right. \\
& \left.+\beta_{n}\left\|S_{1} s_{n}-p\right\|^{2}-\left(1-\beta_{n}\right) \beta_{n}\left\|S_{1} s_{n}-s_{n}\right\|^{2}\right) \\
\leq & \left\|s_{n}-p\right\|^{2}-\alpha_{n}\left(1-\beta_{n}\right) \beta_{n}\left\|S_{1} s_{n}-s_{n}\right\|^{2} .
\end{aligned}
$$

This implies that

$$
\alpha_{n}\left(1-\beta_{n}\right) \beta_{n}\left\|S_{1} s_{n}-s_{n}\right\|^{2} \leq\left\|s_{n}-p\right\|^{2}-\left\|z_{n}-p\right\|^{2} .
$$

From our assumptions and (3.6), we have

$$
\lim _{n \rightarrow \infty}\left\|S_{1} s_{n}-s_{n}\right\|=0 .
$$

This implies that

$$
\lim _{n \rightarrow \infty}\left\|y_{n}-s_{n}\right\|=\lim _{n \rightarrow \infty} \beta_{n}\left\|S_{1} s_{n}-s_{n}\right\|=0 .
$$

It follows from (3.7) and (3.11) that

$$
\left\|S_{2} y_{n}-y_{n}\right\| \leq\left\|S_{2} y_{n}-s_{n}\right\|+\left\|s_{n}-y_{n}\right\| \rightarrow 0,
$$

as $n \rightarrow \infty$. By Lemma 1, (3.10), (3.11) and (3.12), we have $w \in F$.

Step 5. Show that $w=v=P_{F} s_{1}$. Since $s_{n}=P_{C_{n}} s_{1}$, we have

$$
\left\langle s_{1}-s_{n}, s_{n}-p\right\rangle \geq 0, \forall p \in C_{n} .
$$

By taking the limit in (3.13), we obtain

$$
\left\langle s_{1}-w, w-p\right\rangle \geq 0, \quad \forall p \in C_{n} .
$$

Since $F \subset C_{n}$, so $w=P_{F} s_{1}$. This completes the proof. 
Theorem 2. Let $C$ be a nonempty closed and convex subset of a real Hilbert space $H$ and let $G=(V(G), E(G))$ be a directed graph such that $V(G)=C$ and $E(G)$ is convex. Let $S_{1}, S_{2}: C \rightarrow C$ be $G$-nonexpansive mappings such that $F:=$ $F\left(S_{1}\right) \cap F\left(S_{2}\right) \neq \varnothing, F$ is closed and $F\left(S_{i}\right) \times F\left(S_{i}\right) \subseteq E(G)$ for all $i=1,2$. Let $\left\{t_{n}\right\}$ be a sequence generated by

$$
\begin{aligned}
t_{1} & \in C, \text { with } C_{1}=C, \\
y_{n} & =\left(1-\beta_{n}\right) t_{n}+\beta_{n} S_{1} t_{n}, \\
z_{n} & =\left(1-\alpha_{n}\right) y_{n}+\alpha_{n} S_{2} y_{n}, \\
C_{n+1} & =\left\{z \in C_{n}:\left\|z_{n}-z\right\| \leq\left\|t_{n}-z\right\|\right\}, \\
t_{n+1} & =P_{C_{n+1}} t_{1}, n \geq 1,
\end{aligned}
$$

where $\left\{\alpha_{n}\right\},\left\{\beta_{n}\right\} \subset[0,1]$. Assume that the following conditions hold:

(i) $\left\{t_{n}\right\}$ dominates $p$ for all $p \in F$ and if there exists a subsequence $\left\{t_{n_{k}}\right\}$ of $\left\{t_{n}\right\}$ such that $t_{n_{k}} \rightarrow w \in C$, then $\left(t_{n_{k}}, w\right) \in E(G)$;

(ii) $\liminf _{n \rightarrow \infty} \alpha_{n}>0$; (iii) $0<\liminf _{n \rightarrow \infty} \beta_{n} \leq \limsup _{n \rightarrow \infty} \beta_{n}<1$.

Then the sequence $\left\{t_{n}\right\}$ converges strongly to $P_{F} t_{1}$.

Proof. We set $t_{n}=s_{n}$, by the same proof of Step 1 in Theorem 1, we have $P_{F} t_{1}$ well-defined, $C_{n+1}$ is closed convex for all $n \in \mathbb{N}$ and $\left(y_{n}, p\right) \in E(G)$ for each $p \in F$. Since $S_{1}, S_{2}$ are edge-preserving, we have

$$
\begin{aligned}
\left\|z_{n}-p\right\| & \leq\left(1-\alpha_{n}\right)\left\|y_{n}-p\right\|+\alpha_{n}\left\|S_{2} y_{n}-p\right\| \\
& \leq\left(1-\beta_{n}\right)\left\|t_{n}-p\right\|+\beta_{n}\left\|S_{1} t_{n}-p\right\| \leq\left\|t_{n}-p\right\| .
\end{aligned}
$$

We can conclude that $p \in C_{n+1}$. Thus $F \subset C_{n+1}$. This implies that $P_{C_{n+1}} t_{1}$ is welldefined. By the same proof of Step 2-3 in Theorem 1, we obtain $t_{n} \rightarrow w \in C$ as $n \rightarrow \infty$. We next show that $w \in F$. Since $t_{n+1} \in C_{n}$, it follows from (3.5) that

$$
\left\|z_{n}-t_{n}\right\| \leq\left\|z_{n}-t_{n+1}\right\|+\left\|t_{n+1}-t_{n}\right\| \leq 2\left\|t_{n+1}-t_{n}\right\| \rightarrow 0
$$

as $n \rightarrow \infty$. Since $\left\{t_{n}\right\}$ dominates $p$ for all $p \in F$, we get

$$
\begin{aligned}
\left\|z_{n}-p\right\|^{2} & \leq\left(1-\alpha_{n}\right)\left\|y_{n}-p\right\|^{2}+\alpha_{n}\left\|S_{2} y_{n}-p\right\|^{2} \\
& \leq\left(1-\beta_{n}\right)\left\|t_{n}-p\right\|^{2}+\beta_{n}\left\|S_{1} t_{n}-p\right\|^{2}-\left(1-\beta_{n}\right) \beta_{n}\left\|S_{1} t_{n}-t_{n}\right\|^{2} \\
& \leq\left\|t_{n}-p\right\|^{2}-\left(1-\beta_{n}\right) \beta_{n}\left\|S_{1} t_{n}-t_{n}\right\|^{2} .
\end{aligned}
$$

This implies that

$$
\left(1-\beta_{n}\right) \beta_{n}\left\|S_{1} t_{n}-t_{n}\right\|^{2} \leq\left\|t_{n}-p\right\|^{2}-\left\|z_{n}-p\right\|^{2} .
$$

From our assumption (ii) and (3.18), we have

$$
\lim _{n \rightarrow \infty}\left\|S_{1} t_{n}-t_{n}\right\|=0 .
$$

This implies that

$$
\lim _{n \rightarrow \infty}\left\|y_{n}-t_{n}\right\|=\lim _{n \rightarrow \infty} \beta_{n}\left\|S_{1} t_{n}-t_{n}\right\|=0
$$


It follows from (3.16) and (3.20) that

$$
\left\|y_{n}-z_{n}\right\| \leq\left\|y_{n}-t_{n}\right\|+\left\|t_{n}-z_{n}\right\| \rightarrow 0,
$$

as $n \rightarrow \infty$. From $\liminf _{n \rightarrow \infty} \alpha_{n}>0$ and (3.21), we have

$$
\lim _{n \rightarrow \infty}\left\|S_{2} y_{n}-y_{n}\right\|=\lim _{n \rightarrow \infty} \frac{1}{\alpha_{n}}\left\|z_{n}-y_{n}\right\|=0 \text {. }
$$

By Lemma 1, (3.19), (3.20) and (3.22), we have $w \in F$. From Step 5 in Theorem 1, we obtain $w=P_{F} t_{1}$. This completes the proof.

Theorem 3. Let $C$ be a nonempty closed and convex subset of a real Hilbert space $H$ and let $G=(V(G), E(G))$ be a directed graph such that $V(G)=C$ and $E(G)$ is convex. Let $S_{1}, S_{2}: C \rightarrow C$ be $G$-nonexpansive mappings such that $F:=$ $F\left(S_{1}\right) \cap F\left(S_{2}\right) \neq \varnothing, F$ is closed and $F\left(S_{i}\right) \times F\left(S_{i}\right) \subseteq E(G)$ for all $i=1,2$. Let $\left\{u_{n}\right\}$ be a sequence generated by

$$
\begin{aligned}
u_{1} & \in C, \text { with } C_{1}=C, \\
y_{n} & =\left(1-\beta_{n}\right) u_{n}+\beta_{n} S_{1} u_{n}, \\
z_{n} & =\left(1-\alpha_{n}\right) S_{1} u_{n}+\alpha_{n} S_{2} y_{n}, \\
C_{n+1} & =\left\{z \in C_{n}:\left\|z_{n}-z\right\| \leq\left\|u_{n}-z\right\|\right\}, \\
u_{n+1} & =P_{C_{n+1}} u_{1}, n \geq 1,
\end{aligned}
$$

where $\left\{\alpha_{n}\right\},\left\{\beta_{n}\right\} \subset[0,1]$. Assume that the following conditions hold:

(i) $\left\{u_{n}\right\}$ dominates $p$ for all $p \in F$ and if there exists a subsequence $\left\{u_{n_{k}}\right\}$ of $\left\{u_{n}\right\}$ such that $u_{n_{k}} \rightarrow w \in C$, then $\left(u_{n_{k}}, w\right) \in E(G)$;

(ii) $0<\liminf _{n \rightarrow \infty} \alpha_{n} \leq \limsup _{n \rightarrow \infty} \alpha_{n}<1$;

(iii) $0<\liminf _{n \rightarrow \infty} \beta_{n} \leq \limsup _{n \rightarrow \infty} \beta_{n}<1$.

Then the sequence $\left\{u_{n}\right\}$ converges strongly to $P_{F} u_{1}$.

Proof. We set $u_{n}=s_{n}$, by the same proof of Step 1 in Theorem 1, we have $P_{F} u_{1}$ well-defined, $C_{n+1}$ is closed convex for all $n \in \mathbb{N}$ and $\left(y_{n}, p\right) \in E(G)$ for each $p \in F$. Since $S_{1}, S_{2}$ are edge-preserving, we have

$$
\begin{aligned}
\left\|z_{n}-p\right\| & \leq\left(1-\alpha_{n}\right)\left\|S_{1} u_{n}-p\right\|+\alpha_{n}\left\|S_{2} y_{n}-p\right\| \\
& \leq\left(1-\alpha_{n}\right)\left\|u_{n}-p\right\|+\alpha_{n}\left(\left(1-\beta_{n}\right)\left\|u_{n}-p\right\|+\beta_{n}\left\|S_{1} u_{n}-p\right\|\right) \\
& \leq\left\|u_{n}-p\right\| .
\end{aligned}
$$

We can conclude that $p \in C_{n+1}$. Thus $F \subset C_{n+1}$. This implies that $P_{C_{n+1}} u_{1}$ is well-defined. By the same proof of Step 2-3 in Theorem 1, we obtain $u_{n} \rightarrow w \in C$ as $n \rightarrow \infty$. We next show that $w \in F$. Since $u_{n+1} \in C_{n}$, it follows from (3.5) that

$$
\left\|z_{n}-u_{n}\right\| \leq\left\|z_{n}-u_{n+1}\right\|+\left\|u_{n+1}-u_{n}\right\| \leq 2\left\|u_{n+1}-u_{n}\right\| \rightarrow 0
$$

as $n \rightarrow \infty$. Since $\left\{u_{n}\right\}$ dominates $p$ for all $p \in F$, we get

$$
\left\|z_{n}-p\right\|^{2} \leq\left(1-\alpha_{n}\right)\left\|S_{1} u_{n}-p\right\|^{2}+\alpha_{n}\left\|S_{2} y_{n}-p\right\|^{2}
$$




$$
\begin{aligned}
\leq & \left(1-\alpha_{n}\right)\left\|u_{n}-p\right\|^{2}+\alpha_{n}\left(\left(1-\beta_{n}\right)\left\|u_{n}-p\right\|^{2}\right. \\
& \left.+\beta_{n}\left\|S_{1} u_{n}-p\right\|^{2}-\left(1-\beta_{n}\right) \beta_{n}\left\|S_{1} u_{n}-u_{n}\right\|^{2}\right) \\
\leq & \left\|u_{n}-p\right\|^{2}-\alpha_{n}\left(1-\beta_{n}\right) \beta_{n}\left\|S_{1} u_{n}-u_{n}\right\|^{2} .
\end{aligned}
$$

This implies that

$$
\left(1-\beta_{n}\right) \beta_{n}\left\|S_{1} u_{n}-u_{n}\right\|^{2} \leq\left\|u_{n}-p\right\|^{2}-\left\|z_{n}-p\right\|^{2} .
$$

From our assumption (ii) and (3.27), we have

$$
\lim _{n \rightarrow \infty}\left\|S_{1} u_{n}-u_{n}\right\|=0 .
$$

This implies that

$$
\lim _{n \rightarrow \infty}\left\|y_{n}-u_{n}\right\|=\lim _{n \rightarrow \infty} \beta_{n}\left\|S_{1} u_{n}-u_{n}\right\|=0 .
$$

It follows from (3.28) and (3.29) that

$$
\left\|S_{1} u_{n}-y_{n}\right\| \leq\left\|S_{1} u_{n}-u_{n}\right\|+\left\|u_{n}-y_{n}\right\| \rightarrow 0,
$$

as $n \rightarrow \infty$. For $p \in F$, it follows from (3.24) that

$$
\begin{aligned}
\left\|z_{n}-p\right\|^{2} & =\left(1-\alpha_{n}\right)\left\|S_{1} u_{n}-p\right\|^{2}+\alpha_{n}\left\|S_{2} y_{n}-p\right\|^{2}-\left(1-\alpha_{n}\right) \alpha_{n}\left\|S_{1} u_{n}-S_{2} y_{n}\right\|^{2} \\
& \leq\left(1-\alpha_{n}\right)\left\|u_{n}-p\right\|^{2}+\alpha_{n}\left\|y_{n}-p\right\|^{2}-\left(1-\alpha_{n}\right) \alpha_{n}\left\|S_{1} u_{n}-S_{2} y_{n}\right\|^{2} \\
& \leq\left\|u_{n}-p\right\|^{2}-\left(1-\alpha_{n}\right) \alpha_{n}\left\|S_{1} u_{n}-S_{2} y_{n}\right\|^{2} .
\end{aligned}
$$

This implies that

$$
\left(1-\alpha_{n}\right) \alpha_{n}\left\|S_{1} u_{n}-S_{2} y_{n}\right\|^{2} \leq\left\|u_{n}-p\right\|^{2}-\left\|z_{n}-p\right\|^{2} .
$$

From the assumption (i) and (3.25), we have

$$
\lim _{n \rightarrow \infty}\left\|S_{1} u_{n}-S_{2} y_{n}\right\|=0 .
$$

It follows from (3.30) and (3.32) that

$$
\left\|S_{2} y_{n}-y_{n}\right\| \leq\left\|S_{2} y_{n}-S_{1} u_{n}\right\|+\left\|S_{1} u_{n}-y_{n}\right\| \rightarrow 0,
$$

as $n \rightarrow \infty$.

$$
\lim _{n \rightarrow \infty}\left\|S_{2} y_{n}-y_{n}\right\|=\lim _{n \rightarrow \infty} \frac{1}{\alpha_{n}}\left\|z_{n}-y_{n}\right\|=0 .
$$

By Lemma 1, (3.28), (3.29) and (3.34), we have $w \in F$. From Step 5 in Theorem 1, we obtain $w=P_{F} u_{1}$. This completes the proof.

Theorem 4. Let $C$ be a nonempty closed and convex subset of a real Hilbert space $H$ and let $G=(V(G), E(G))$ be a directed graph such that $V(G)=C, E(G)$ is convex and $G$ is transitive. Let $S_{1}, S_{2}: C \rightarrow C$ be G-nonexpansive mappings such that $F:=F\left(S_{1}\right) \cap F\left(S_{2}\right) \neq \varnothing, F$ is closed and $F\left(S_{i}\right) \times F\left(S_{i}\right) \subseteq E(G)$ for all $i=1,2$. Let $\left\{v_{n}\right\}$ be a sequence generated by

$$
v_{1} \in C, \text { with } C_{1}=C
$$




$$
\begin{aligned}
y_{n} & =\left(1-\beta_{n}\right) v_{n}+\beta_{n} S_{1} v_{n}, \\
z_{n} & =\left(1-\alpha_{n}\right) S_{1} y_{n}+\alpha_{n} S_{2} y_{n}, \\
C_{n+1} & =\left\{z \in C_{n}:\left\|z_{n}-z\right\| \leq\left\|v_{n}-z\right\|\right\}, \\
v_{n+1} & =P_{C_{n+1}} v_{1}, n \geq 1,
\end{aligned}
$$

where $\left\{\alpha_{n}\right\},\left\{\beta_{n}\right\} \subset[0,1]$. Assume that the following conditions hold:

(i) $\left(v_{n}, p\right),\left(p, v_{n}\right) \in E(G)$ for all $p \in F$ and $n \in \mathbb{N}$ and if there exists a subsequence $\left\{v_{n_{k}}\right\}$ of $\left\{v_{n}\right\}$ such that $v_{n_{k}} \rightarrow w \in C$, then $\left(v_{n_{k}}, w\right) \in E(G)$;

(ii) $0<\liminf _{n \rightarrow \infty} \alpha_{n} \leq \limsup _{n \rightarrow \infty} \alpha_{n}<1$;

(iii) $0<\liminf _{n \rightarrow \infty} \beta_{n} \leq \limsup _{n \rightarrow \infty} \beta_{n}<1$.

Then the sequence $\left\{x_{n}\right\}$ converges strongly to $P_{F} v_{1}$.

Proof. We set $v_{n}=s_{n}$, by the same proof of Step 1 in Theorem 1, we have $P_{F} v_{1}$ well-defined, $C_{n+1}$ is closed convex for all $n \in \mathbb{N}$ and $\left(y_{n}, p\right) \in E(G)$ for each $p \in F$. Since $S_{1}, S_{2}$ are edge-preserving, we have

$$
\begin{aligned}
\left\|z_{n}-p\right\| & \leq\left(1-\alpha_{n}\right)\left\|S_{1} y_{n}-p\right\|+\alpha_{n}\left\|S_{2} y_{n}-p\right\| \\
& \leq\left(1-\beta_{n}\right)\left\|v_{n}-p\right\|+\beta_{n}\left\|S_{1} v_{n}-p\right\| \\
& \leq\left\|v_{n}-p\right\| .
\end{aligned}
$$

We can conclude that $p \in C_{n+1}$. Thus $F \subset C_{n+1}$. This implies that $P_{C_{n+1}} v_{1}$ is well-defined. By the same proof of Step 2-3 in Theorem 1, we obtain $v_{n} \rightarrow w \in C$ as $n \rightarrow \infty$. We next show that $w \in F$. Since $v_{n+1} \in C_{n}$, it follows from (3.5) that

$$
\left\|z_{n}-v_{n}\right\| \leq\left\|z_{n}-v_{n+1}\right\|+\left\|v_{n+1}-v_{n}\right\| \leq 2\left\|v_{n+1}-v_{n}\right\| \rightarrow 0
$$

as $n \rightarrow \infty$. Since $\left\{v_{n}\right\}$ dominates $p$ for all $p \in F$, we get

$$
\begin{aligned}
\left\|z_{n}-p\right\|^{2} & \leq\left(1-\alpha_{n}\right)\left\|S_{1} y_{n}-p\right\|^{2}+\alpha_{n}\left\|S_{2} y_{n}-p\right\|^{2} \\
& \left.\leq\left(1-\beta_{n}\right)\left\|v_{n}-p\right\|^{2}+\beta_{n}\left\|S_{1} v_{n}-p\right\|^{2}-\left(1-\beta_{n}\right) \beta_{n}\left\|S_{1} v_{n}-v_{n}\right\|^{2}\right) \\
& \leq\left\|v_{n}-p\right\|^{2}-\left(1-\beta_{n}\right) \beta_{n}\left\|S_{1} v_{n}-v_{n}\right\|^{2} .
\end{aligned}
$$

This implies that

$$
\left(1-\beta_{n}\right) \beta_{n}\left\|S_{1} v_{n}-v_{n}\right\|^{2} \leq\left\|v_{n}-p\right\|^{2}-\left\|z_{n}-p\right\|^{2} .
$$

From our assumption (ii) and (3.39), we have

$$
\lim _{n \rightarrow \infty}\left\|S_{1} v_{n}-v_{n}\right\|=0 .
$$

This implies that

$$
\lim _{n \rightarrow \infty}\left\|y_{n}-v_{n}\right\|=\lim _{n \rightarrow \infty} \beta_{n}\left\|S_{1} v_{n}-v_{n}\right\|=0 .
$$

It follows from (3.37) and (3.41) that

$$
\left\|y_{n}-z_{n}\right\| \leq\left\|y_{n}-v_{n}\right\|+\left\|v_{n}-z_{n}\right\| \rightarrow 0,
$$


as $n \rightarrow \infty$. We next show that $\left(v_{n}, y_{n}\right) \in E(G)$ for all $n \in \mathbb{N}$. Let $p \in F$. Since $\left(p, v_{n}\right) \in E(G)$ and $S_{1}$ is edge-preserving, so $\left(p, S_{1} v_{n}\right) \in E(G)$ for all $n \in \mathbb{N}$. Then, $\left(p, y_{n}\right)=\left(p,\left(1-\beta_{n}\right) v_{n}+\beta_{n} S_{1} v_{n}\right) \in E(G)$ by $E(G)$ is convex. Since $G$ is transitive, $\left(v_{n}, y_{n}\right) \in E(G)$. This implies that

$$
\begin{aligned}
\left\|S_{1} y_{n}-y_{n}\right\| & \leq\left\|S_{1} y_{n}-S_{1} v_{n}\right\|+\left\|S_{1} v_{n}-v_{n}\right\|+\left\|v_{n}-y_{n}\right\| \\
& \leq 2\left\|y_{n}-S_{1} v_{n}\right\|+\left\|S_{1} v_{n}-v_{n}\right\| .
\end{aligned}
$$

It follows from (3.40), (3.41) and (3.43) that

$$
\lim _{n \rightarrow \infty}\left\|S_{1} y_{n}-y_{n}\right\|=0 .
$$

It follows from (3.42) and (3.43) that

$$
\left\|S_{1} y_{n}-z_{n}\right\| \leq\left\|S_{1} y_{n}-y_{n}\right\|+\left\|y_{n}-z_{n}\right\| \rightarrow 0,
$$

as $n \rightarrow \infty$. From $\liminf _{n \rightarrow \infty} \alpha_{n}>0$ and (3.44), we have

$$
\lim _{n \rightarrow \infty}\left\|S_{2} y_{n}-z_{n}\right\|=\lim _{n \rightarrow \infty} \frac{1}{\alpha_{n}}\left\|z_{n}-S_{1} y_{n}\right\|=0 .
$$

It follows from (3.42) and (3.46) that

$$
\left\|S_{2} y_{n}-y_{n}\right\| \leq\left\|S_{2} y_{n}-z_{n}\right\|+\left\|z_{n}-y_{n}\right\| \rightarrow 0,
$$

as $n \rightarrow \infty$. By Lemma 1, (3.41), (3.43) and (3.46), we have $w \in F$. From Step 5 in Theorem 1, we obtain $w=P_{F} v_{1}$. This completes the proof.

\section{Convergence Rate}

In this section, we give examples and numerical results for supporting our main theorem. Moreover, we compare convergence rate of all iterations in Theorem 1-4. In 1976, Rhoades [17] gave the idea how to compare the rate of convergence between two iterative methods as follows:

Definition 7 ([17]). Let $C$ be a nonempty closed convex subset of a Banach space $X$ and $S: C \rightarrow C$ be be a mapping. Suppose $\left\{x_{n}\right\}$ and $\left\{y_{n}\right\}$ are two iterations which converge to a fixed point $p$ of $S$. Then $\left\{x_{n}\right\}$ is said to converge faster than $\left\{y_{n}\right\}$ if

$$
\left\|x_{n}-p\right\| \leq\left\|y_{n}-p\right\|
$$

for all $n \geq 1$.

In 2011, Phuengrattana and Suantai [14] showed that the Ishikawa iteration converges faster than the Mann iteration for a class of continuous functions on the closed interval in a real line. In order to study, the order of convergence of a real sequence $\left\{x_{n}\right\}$ converging to $p$, we usually use the well-known terminology in numerical analysis, see [7], for example. 
Definition 8 ([7]). Suppose $\left\{x_{n}\right\}$ is a sequence that converges to $p$, with $x_{n} \neq p$ for all $n$. If positive constants $a$ and $b$ exist with

$$
\lim _{n \rightarrow \infty} \frac{\left|x_{n+1}-p\right|}{\left|x_{n}-p\right|^{b}}=a
$$

then $\left\{x_{n}\right\}$ converges to $p$ of order $a$, with asymptotic error constant $b$. If $b=1$ (and $a<1$ ), the sequence is linearly convergent and if $b=2$, the sequence is quadratically convergent.

In 2002, Berinde [5] employed above concept for comparing the rate of convergence between the two iterative methods as follows:

Definition 9 ([5]). Let $\left\{x_{n}\right\}$ and $\left\{y_{n}\right\}$ be two sequences of positive numbers that converge to $p, q$,respectively. Assume there exists

$$
\lim _{n \rightarrow \infty} \frac{\left|x_{n}-p\right|}{\left|y_{n}-q\right|}=\ell
$$

(i) If $\ell=0$, then it is said that the sequence $\left\{x_{n}\right\}$ converges to $p$ faster than the sequence $\left\{y_{n}\right\}$ to $q$.

(ii) If $0<\ell<\infty$, then we say that the sequence $\left\{x_{n}\right\}$ and $\left\{y_{n}\right\}$ have the same rate of convergence.

Definition $10([5,15])$. Let $\mathrm{C}$ be a nonempty closed convex subset of a Banach space $X$ and $S: C \rightarrow C$ be a mapping. Suppose $\left\{x_{n}\right\}$ and $\left\{y_{n}\right\}$ are two iterations which converge to $p$ fixed point $q$ of $S$. We say that $\left\{x_{n}\right\}$ converges faster than $\left\{y_{n}\right\}$ to $q$ if

$$
\lim _{n \rightarrow \infty} \frac{\left\|x_{n}-p\right\|}{\left\|y_{n}-q\right\|}=0
$$

We now give an example in Euclidian space $\mathbb{R}^{3}$ which shows numerical experiment for supporting our main results and comparing the rate of convergence of all iterations in Theorem 1-4.

Example 1. Let $H=\mathbb{R}^{3}$ and $C=[-2,0]^{3}$. Assume that $(x, y) \in E(G)$ if and only if $-1.5 \leq x_{i}, y_{i} \leq-0.5$ or $x=y$ for all $x=\left(x_{1}, x_{2}, x_{3}\right), y=\left(y_{1}, y_{2}, y_{3}\right) \in$ $C$. Define a mappings $S_{1}, S_{2}: C \rightarrow C$ by $S_{1} x=\left(\frac{\arcsin \left(x_{1}+1\right)}{2}-1, \log \left(x_{2}+2\right)-\right.$ $1,-1)$ and $S_{2} x=\left(-1,-1, \frac{\cot \left(x_{3}-\frac{\pi}{2}+1\right)}{2}-1\right)$ for all $x=\left(x_{1}, x_{2}, x_{3}\right) \in C$. It is easy to check that $S_{1}$ and $S_{2}$ are G-nonexpansive such that $F\left(S_{1}\right) \cap F\left(S_{2}\right)=\{(-1,-1,-1)\}$. On the other hand, $S_{1}$ is not nonexpansive since for $x=(-2,-1.46,-1)$ and $y=$ $(-1.49,-1.82,-1)$. This implies that $\left\|S_{1}(x)-S_{1}(y)\right\|>0.70>\|x-y\|$. Moreover, $S_{2}$ is not nonexpansive since for $x=(-1,-1,-1.55)$ and $y=(-1,-1,-1.97)$, we have $\left\|S_{2}(x)-S_{2}(y)\right\|>0.42>\|x-y\|$. 
We provide a numerical test of a comparison of all iterations in Theorem 1-4 and choose $\alpha_{n}=\frac{n+1}{5 n+3}, \beta_{n}=\frac{n+3}{10 n+5}$. The stoping criterion is defined by $\left\|x_{n+1}-x_{n}\right\|<$ $10^{-7}$. The different choices of $x_{0}$ are given in Table 1 .

TABLE 1. Comparison the methods in Theorem 1-4 of Example 1

\begin{tabular}{ccccc}
\hline Iterations & $\begin{array}{c}\text { Choice 1: } \\
\text { Iterations } \\
\text { Number }\end{array}$ & $\begin{array}{c}(-25,-0.9,-0.65) \\
\text { CPU Time } \\
(\mathrm{sec})\end{array}$ & $\begin{array}{c}\text { Choice 2: } \\
\text { Iterations } \\
\text { Number }\end{array}$ & $\begin{array}{c}(-1.45,-1.2,-0.7) \\
\text { CPU Time } \\
(\mathrm{sec})\end{array}$ \\
\hline$(3.1)$ & 118 & $2.344643 \mathrm{e}-03$ & 124 & $1.618338 \mathrm{e}-03$ \\
$(3.15)$ & 97 & $2.896767 \mathrm{e}-03$ & 102 & $1.452308 \mathrm{e}-03$ \\
$(3.23)$ & 39 & $2.051223 \mathrm{e}-03$ & 41 & $1.233451 \mathrm{e}-03$ \\
$(3.35)$ & 38 & $3.913172 \mathrm{e}-03$ & 39 & $3.129209 \mathrm{e}-03$
\end{tabular}

By computing, we obtain the sequences $\left\{x_{n}\right\}$ generated in Theorem 1-4 converge to $(-1,-1,-1)$. We next show the following error plots of $\left\|x_{n+1}-x_{n}\right\|$.
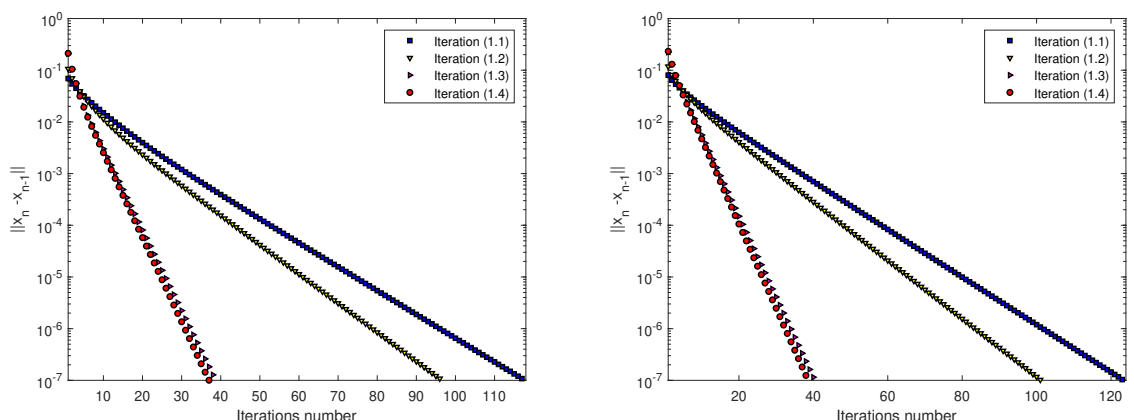

FIGURE 1. Error plots for sequences $\left\{x_{n}\right\}$ in Table 1 of choice 1 and choice 2 , respectively.

We note that $p=(-1,-1,-1)$ is a common fixed point of $S_{1}$ and $S_{2}$. We compare the rate of convergence of $\left\{s_{n}\right\},\left\{t_{n}\right\},\left\{u_{n}\right\}$ and $\left\{v_{n}\right\}$ for Choice 1: $x_{0}=(-1.25,-0.9,-0.65)$ and Choice 2: $x_{0}=(-1.45,-1.2,-0.7)$. 
TABLE 2. Comparison the rate of convergence of all iterations in Theorem 1-4 of Example 1 by choosing $x_{0}=(-1.25,-0.9,-0.65)$

\begin{tabular}{ccccccc}
\hline $\mathrm{n}$ & $\frac{\left\|v_{n}-p\right\|}{\left\|s_{n}-p\right\|}$ & $\frac{\left\|v_{n}-p\right\|}{\left\|t_{n}-p\right\|}$ & $\frac{\left\|v_{n}-p\right\|}{\left\|u_{n}-p\right\|}$ & $\frac{\left\|u_{n}-p\right\|}{\left\|s_{n}-p\right\|}$ & $\frac{\left\|u_{n}-p\right\|}{\left\|t_{n}-p\right\|}$ & $\frac{\left\|t_{n}-p\right\|}{\left\|s_{n}-p\right\|}$ \\
\hline 0 & 1.000000 & 1.000000 & 1.000000 & 1.000000 & 1.000000 & 1.000000 \\
1 & 0.637538 & 0.979056 & 0.704657 & 0.651176 & 0.719731 & 0.904749 \\
2 & 0.434675 & 0.952151 & 0.515409 & 0.456519 & 0.541310 & 0.843360 \\
3 & 0.314266 & 0.924612 & 0.394249 & 0.339890 & 0.426395 & 0.797125 \\
4 & 0.236078 & 0.899949 & 0.310695 & 0.262324 & 0.345236 & 0.759841 \\
5 & 0.181039 & 0.878591 & 0.248470 & 0.206056 & 0.282805 & 0.728615 \\
6 & 0.140193 & 0.859748 & 0.199756 & 0.163063 & 0.232342 & 0.701821 \\
7 & 0.095220 & 0.842647 & 0.160677 & 0.113001 & 0.190681 & 0.592617 \\
8 & 0.074299 & 0.826834 & 0.129054 & 0.089860 & 0.156083 & 0.575721 \\
9 & 0.057963 & 0.811696 & 0.103409 & 0.071409 & 0.127399 & 0.560516
\end{tabular}

TABLE 3. Comparison the rate of convergence of all iterations in Theorem 1-4 of Example 1 by choosing $x_{0}=(-1.45,-1.2,-0.7)$

\begin{tabular}{ccccccc}
\hline $\mathrm{n}$ & $\frac{\left\|v_{n}-p\right\|}{\left\|s_{n}-p\right\|}$ & $\frac{\left\|v_{n}-p\right\|}{\left\|t_{n}-p\right\|}$ & $\frac{\left\|v_{n}-p\right\|}{\left\|u_{n}-p\right\|}$ & $\frac{\left\|u_{n}-p\right\|}{\left\|s_{n}-p\right\|}$ & $\frac{\left\|u_{n}-p\right\|}{\left\|t_{n}-p\right\|}$ & $\frac{\left\|t_{n}-p\right\|}{\left\|s_{n}-p\right\|}$ \\
\hline 0 & 1.000000 & 1.000000 & 1.000000 & 1.000000 & 1.000000 & 1.000000 \\
1 & 0.713514 & 0.966823 & 0.768432 & 0.737998 & 0.794801 & 0.928531 \\
2 & 0.527376 & 0.937880 & 0.598780 & 0.562306 & 0.638440 & 0.880750 \\
3 & 0.397672 & 0.913037 & 0.471501 & 0.435549 & 0.516410 & 0.843417 \\
4 & 0.302854 & 0.891493 & 0.372931 & 0.339716 & 0.418322 & 0.812092 \\
5 & 0.231693 & 0.872302 & 0.295256 & 0.265611 & 0.338479 & 0.784719 \\
6 & 0.177594 & 0.854743 & 0.233630 & 0.207774 & 0.273334 & 0.760149 \\
7 & 0.136232 & 0.838398 & 0.184673 & 0.162490 & 0.220269 & 0.737690 \\
8 & 0.104523 & 0.822910 & 0.145806 & 0.127016 & 0.177183 & 0.716861 \\
9 & 0.080194 & 0.808107 & 0.114999 & 0.099237 & 0.142307 & 0.697345
\end{tabular}

Remark 1. From Figure 1, Table 1-3, it is shown that the iteration (3.35) has a good convergence speed and requires small number of iterations than the other three iterations for each of the choices.

\section{ACKNOWLEDGEMENT}

W. Cholamjiak and D. Yambangwai would like to thank University of Phayao, Phayao, Thailand (Grant No. UoE62001). H. A. Hammad would like to thank Sohag University. 


\section{REFERENCES}

[1] R. Agarwal, D. O'Regan, and D. Sahu, "Iterative construction of fixed points of nearly asymptotically nonexpansive mappings." J. Nonlinear Convex. Anal., vol. 8, no. 1, pp. 61-79, 2007.

[2] R. Agarwal, D. O'Regan, and D. Sahu, Fixed Point Theory for Lipschitzian-Type Mappings with Applications, Topological Fixed Point Theory and Its Applications. New York: Springer-Verlag, 2009, vol. 6, doi: 10.1007/978-0-387-75818-3.

[3] M. Alfuraidan and M. Khamsi, "Fixed points of monotone nonexpansive mappings on a hyperbolic metric space with a graph.” Fixed Point Theory Appl., no. 44, 2015, doi: 10.1186/s13663-0150294-5.

[4] S. Banach, "Sur les opérations dans les ensembles abstraits et leur applications aux équations intégrales." Fundamenta Math., vol. 3, no. 1, pp. 133-181, 1922, doi: 10.4064/fm-3-1-133-181.

[5] V. Berinde, Iterative Approximation of Fixed Points. Baia Mare: Editura Efemeride, 2002. doi: 10.1007/978-3-540-72234-2.

[6] F. Browder, "Nonexpansive nonlinear operators in a Banach space." Proc. Nat. Acad. Sci. USA., vol. 54, no. 4, pp. 1041-1044, 1965, doi: 10.1073/pnas.54.4.1041.

[7] R. Burden and J. Faires, Numerical Analysis., 9th ed. Boston: Brooks/Cole Cengage Learning, 2010. doi: 10.4236/jep.2014.512106.

[8] S. Ishikawa, "Fixed points by a new iteration method." Proc. Amer. Math. Soc., vol. 44, no. 1, pp. 147-150, 1974, doi: 10.1090/S0002-9939-1974-0336469-5.

[9] J. Jachymski, "The contraction principle for mappings on a metric space with a graph." Proc. Amer. Math. Soc., vol. 136, no. 4, pp. 1359-1373, 2008, doi: doi.org/10.1016/j.camwa.2010.06.003.

[10] T. Kim and H. Xu, "Strongly convergence of modified Mann iterations for with asymptotically nonexpansive mappings and semigroups." Nonlinear Anal., vol. 64, no. 5, pp. 1140-1152, 2006, doi: 10.1016/j.na.2005.05.059.

[11] W. Mann, "Mean value methods in iteration." Proc. Amer. Math. Soc., vol. 4, pp. 506-510, 1953, doi: 10.1090/S0002-9939-1953-0054846-3.

[12] K. Nakajo and W. Takahashi, "Strongly convergence theorems for nonexpansive mappings and nonexpansive semigroups." J. Math. Anal. Appl., vol. 279, no. 2, pp. 372-379, 2003, doi: 10.1016/S0022-247X(02)00458-4.

[13] A. Nicolae, D. O'Regan, and A. Petrusel, "Fixed point theorems for single valued and multivalued generalized contractions in metric spaces endowed with a graph." Georgian Math. J., vol. 18, no. 2, pp. 307-327, 2011, doi: 10.1515/gmj.2011.0019.

[14] W. Phuengrattana and S. Suantai, "On the rate of convergence of Mann, Ishikawa, Noor and SPiterations for continuous functions on an arbitrary interval." J. Comput. Appl. Math., vol. 235, no. 9, pp. 3006-3014, 2011, doi: 10.1016/j.cam.2010.12.022.

[15] W. Phuengrattana and S. Suantai, "Comparison of the rate of convergence of various iterative methods for the class of weak contractions in Banach spaces." Thai J. Math., vol. 11, no. 11, pp. 217-226, 2013, doi: 10.1155/2008/387056.

[16] S. Reich, "Weak convergence theorems for nonexpansive mappings in Banach spaces." J. Math. Anal. Appl., vol. 67, no. 2, pp. 274-276, 1979, doi: 10.1016/0022-247X(79)90024-6.

[17] B. Rhoades, "Comments on two fixed point iteration method." J. Math. Anal. Appl., vol. 56, no. 3, pp. 741-750, 1976, doi: 10.1016/0022-247X(76)90038-X.

[18] J. Schu and W. Takahashi, "Iterative construction of fixed points of asymptotically nonexpansive mapping." J. Math. Anal. Appl., vol. 158, no. 2, pp. 407-413, 1991, doi: 10.1016/0022247X(91)90245-U. 
[19] R. Suparatulatorn and S. S. W. Cholamjiak, "Hybrid methods for a finite family of G-nonexpansive mappings in Hilbert spaces endowed with graphs." AKCE Int. J. Graphs Combinatorics, vol. 14, no. 2, pp. 101-111, 2017, doi: 10.1016/j.akcej.2017.01.001.

[20] R. Suparatulatorn, W. Cholamjiak, and S. Suntai, "A modified $S$-iteration process for $G$ nonexpansive mappings in Banach spaces with graphs." Numer Algor., vol. 77, no. 2, pp. 479-490, 2018, doi: 10.1007/s11075-017-0324-y.

[21] W. Takahashi, Nonlinear Functional Analysis. Yokohama: Yokohama Publishers, 2000.

[22] W. Takahashi, "Fixed point theorems for new nonlinear mappings in a Hilbert space." J. Nonlinear Convex Anal., vol. 11, no. 1, pp. 79-88, 2010.

[23] W. Takahashi, Y. Takeuchi, and R. Kubota, "Strong convergence theorems by hybrid methods for families of nonexpansive mappings in Hilbert spaces." J. Math. Anal. Appl., vol. 341, no. 1, pp. 276-286, 2008, doi: 10.1016/j.jmaa.2007.09.062.

[24] J. Tiammee, A. Kaewkhao, and S. Suntai, "On Browder's convergence theorem and Halpern iteration process for $G$-nonexpansive mappings in Hilbert spaces endowed with graphs." Fixed Point Theory Appl., no. 187, 2015, doi: 10.1186/s13663-015-0436-9.

[25] O. Tripak, "Common fixed points of G-nonexpansive mappings on Banach spaces with a graph." Fixed Point Theory Appl., no. 87, 2016, doi: 10.1186/s13663-016-0578-4.

Authors' addresses

H.A. Hammad

Department of Mathematics, Faculty of Science, Sohag University, Sohag 82524, Egypt

E-mail address: h_elmagd89@yahoo.com

W. Cholamjiak

Department of Mathematics, School of Science, University of Phayao, Phayao 56000, Thailand

E-mail address: watcharaporn.ch@up.ac.th

D. Yambangwai

Department of Mathematics, School of Science, University of Phayao, Phayao 56000, Thailand

E-mail address: damrongsak.ya@up.ac.th

\section{H. Dutta}

Department of Mathematics, Faculty of Science, Gauhati University, Guwahati-781014, India

E-mail address: hemen_dutta08@rediffmail.com 